Sara Gulam

\title{
Nezanesliivi pripovedovalec, fokalizacija in ironija v romanih Stud. chem. Helene Willfüer Vicki Baum in Eine Zierde für den Verein Marieluise Fleißer
}

Ključne besede: Vicki Baum, Marieluise Fleißer, Weimarska republika, pripovedovalec, fokalizacija, ironija, nezanesljivi pripovedovalec

DOI: 10.4312/ars.13.2.317-330

\section{Uvod: cilji in temeljna vprašanja}

Osnovni cilj tega članka bo detekcija fokalizatorja $\mathrm{v}$ pripovednem besedilu, oziroma definicija mehanizmov pripovednega teksta, ki fokalizatorju omogočajo, da postane viden. Izhajajoč iz izjemno ironičnega tona del, izbranih za analizo, bo raziskovana povezava med fokalizatorjem, (nezanesljivim) pripovedovalcem in ironijo. Zato bodo pred analizo odlomkov iz romanov Stud. chem. Helene Willfüer Vicki Baum in Eine Zierde für den Verein Marieluise Fleißer orisane naratološke teorije in pristopi, ki pripomorejo k razumevanju pretočnosti med omenjenimi kategorijami.

Ukvarjala se bom tudi $\mathrm{z}$ vprašanjem, v kolikšni meri je mogoče fokalizatorja izenačiti s pripovedovalcem, oziroma na čem temelji njun odnos. Posledično bom poskusila argumentirati, zakaj je koristno na pripovedovalca in fokalizatorja $\mathrm{v}$ (modernih) ${ }^{1}$ besedilih nasploh, konkretno pa v dveh delih, izbranih za to analizo, gledati kot na pretočne in sinkretične kategorije. V nadaljevanju bom prav tako skušala pojasniti, da fokalizacija in fokalizator pravzaprav nista neke vrste revolucionarno odkritje naratologov, temveč razmeroma pozno ozaveščena kategorija oziroma plat pripovednega besedila.

1 Pod pojmom moderna besedila so $\mathrm{v}$ tem kontekstu mišljena besedila, ki so nastala kot inovativno nasprotje tradicionalni literaturi in ki preizprašujejo družbene in socialne spremembe poznega 19. in začetka 20. stoletja, oziroma besedila, ki nastajajo v zgodovinskih trenutkih ponovnega vrednotenja in utemeljevanja novih smernic. To so prelomnice, v katerih se tradicija in uveljavljeni obrazci postavljajo pod vprašaj, v katerih se filtrirajo različni vzorci, stereotipi in predpisi delovanja ter utemeljujejo novi. Tovrstne filtracije so morda v določenih trenutkih precej nejasne, a so izjemno pomembne kot signali za nujnost sprememb. V literaturi lahko opazujemo, kako določeni elementi klasičnega preživijo turbulence modernizacije in nekoliko spremenjeni ostanejo vidni v novonastalih, »nestalnih « modernih tvorbah. Za moderna besedila so značilni izrazit individualizem, beg pred resničnostjo, pesimistično razpoloženje, čustvenost, subjektivnost ter stilska in žanrska raznolikost. Termin »Die Moderne« je leta 1890 prvi začel uporabljati za označevanje novih literarnih pojavov fin de siecla avstrijski pisatelj Herman Bahr (prim. Živkovič, 1985, 446-447). 


\subsection{Predmet raziskovanja}

Predmet raziskovanja bosta besedili, nastali v kaotičnem času družbenih in socialnih sprememb pozne Weimarske republike (1928-1933): Stud. chem. Helene Willfüer (1928) avtorice Vicki Baum in Eine Zierde für den Verein (1931) avtorice Marieluise Fleißer. Izbor utemeljujem z izrazito ironičnim in kritičnim tonom del, $\mathrm{v}$ katerih avtorici opozarjata na resne družbene in socialne probleme ter na pasti nespremenjenega delovanja tako posameznika kot družbe v celoti. Vicki Baum nam predstavi težko karierno pot mlade kemičarke Helene, ki v času študija ostane brez očeta in se znajde $\mathrm{v}$ hudi denarni stiski. Vlogo nadomestnega očeta po smrti njenega zunajzakonskega partnerja in očeta njenega otroka prevzame profesor Ambrosius, ki na začetku romana študentko Heleno spoštuje zgolj zaradi dosežkov njenega pokojnega očeta in nekoliko dvomi o njenih sposobnostih, proti koncu romana pa izrazi željo, da bi postala njegova življenjska sopotnica, saj je karierno celo presegla njegove dosežke. Marieluise Fleißer oriše življenjsko prelomnico mlade trgovske potnice Friede, ki mora izbrati med podrejenostjo $\mathrm{v}$ malomeščanski zvezi in svobodnim, a negotovim in tveganim življenjem v branži, v kateri prevladujejo moški. Njen partner Gustl je skraja še nekoliko neodločen in si ne zna predstavljati, kako lahko kot ženska živi samostojno, a jo proti koncu romana grobo zavrže in se s tem dejanjem ponovno afirmira kot dober in časten občan. Ponovno pridobi status, ki ga je izgubil, ko se je zapletel v razmerje s Friedo. V središču obeh romanov sta posameznici in njuni partnerski zvezi, skozi kateri se zrcali njuno spoprijemanje z izzivi spreminjajoče se družbe. Obe deli lahko razumemo kot stičišči meščanskih in delavskih nazorov, kot prizorišči sprememb.

Vodilo naratološke analize obeh del bo poudarek na pretočnosti ter medsebojni prepletenosti pripovedovalca, likov in fokalizatorjev. Iz dosedanjih raziskav je namreč razvidno, da je fokalizacijo nekoliko težje definirati, saj je njen obstoj ozko vezan na odnos pripovedovalca oziroma likov in pripovedne ravni besedila. Mieke Bal ta odnos opiše z naslednjimi besedami: »Fokalizacija temelji na odnosu med videnjem (akterjem, ki gleda) in tistim, kar je videno. [...] fokalizacija je del pripovedi, umeščena je na raven med besedilom in zgodbo. «(Bal, 1997, 146). ${ }^{2}$ Mieke Bal tako utrdi misel, da je zgodba (fabula) pravzaprav rezultat bralčeve interpretacije in »manipulacij» pripovedi (story), saj ta najprej vidi tekst, nato pa formira zgodbo, in ne obratno $(1997,9) .{ }^{3}$ Že z izborom besede agent (in ne denimo pripovedovalec ali lik) se pokaže, kako prepleteno je sožitje treh zgoraj omenjenih kategorij. Fokalizacijo tako lahko

2 Prev. S. G. Mieke Bal v Narratology. Introduction to the theory of narrative uporablja izraz fabula za zgodbo in story za pripoved. Ločuje drugače, kot je v navadi v postklasični naratologiji, ki temelji na dvojni logiki pripovedi med story (fabula, zgodba) in narrative (siže, pripoved).

3 Te navedbe napeljujejo na misel, da sta fabula in fokalizator receptivni kategoriji, ki ju je nemogoče oziroma precej težavno označiti v tekstu. 
razumemo kot kategorijo, ki je intuitivno dojemljiva, a težava nastane, ko jo je treba opisati in sistematizirati, saj jezik zaradi svoje linearnosti težko pričara prepletenost, sinkretičnost in istočasnost.

\section{Kontekst Weimarske republike ${ }^{4}$}

Zaradi boljšega razumevanja pretočnosti in medsebojne prepletenosti pripovedovalca, likov in fokalizatorjev je treba orisati tudi zgodovinski kontekst, v katerem sta deli nastali. Čas Weimarske republike je bil čas političnih rivalstev in nasprotij, v katerem so se za moč in oblast bojevale liberalne in konservativne politične struje, kar je imelo za posledico zelo nestabilno gospodarstvo in naraščajočo brezposelnost. Dodatna ovira pri razvoju države so bile visoke reparacije, ki jih je morala Nemčija plačati po koncu prve svetovne vojne.

Glavna lika obravnavanih del sta mladi ženski, ki si skušata v tem nestabilnem času ustvariti samostojno kariero: Helene, junakinja romana Stud. chem. Helene Willfüer, na znanstvenem področju kot kemičarka in Frieda, glavni lik romana Eine Zierde für den Verein, na trgovskem področju kot samostojna trgovska potnica, prodajalka moke. Za razumevanje prizadevanj obeh likov, ki skušata preseči stereotipe in predsodke takratnega časa, je treba pojasniti še fenomen nove ženske (Neue Frau) v zlatih dvajsetih letih.

Lahko rečemo, da je nova ženska svojevrsten družbeno-kulturni pojav, ki je v dvajsetih letih v weimarski Nemčiji opozarjal na različne vplive na žensko in njeno dojemanje ter na katerega so vplivala družbena, politična, ekonomska in socialna vrenja. Velik vpliv na pojav nove ženske je imela bliskovito razvijajoča se potrošniška kultura. V novih medijih, časopisih za ženske in žepnicah se je razvila idealizirana predstava o ženski: model mlade in revne uslužbenke, ki se poroči s šefom in srečno živi do konca svojih dni. Ta model lahko z minimalnimi spremembami vedno znova apliciramo na široke množice ljudi (prim. Kracauer, 1971, 271-294). Nasprotje tega modela sta med drugim tudi obravnavani deli Stud. chem. Helene Willfüer Vicki Baum in Eine Zierde für den Verein Marieluise Fleißer, ki skušata razkrojiti te stereotipe, saj z opozarjanjem na nasprotja in ambivalence med idealno predstavo o ženskah, ustvarjeno v medijih, in možnostmi takratnega časa osvetljujeta položaj žensk. Kako se to konkretno izrazi v tekstu, bo razloženo nekoliko kasneje. 


\section{Kai je fokalizacija in kako lahko zaznamo fokalizatoria v pripovednem besedilu?}

Pred razčlembo pojmov fokalizacija in fokalizator je treba poudariti, da bosta pripovedni besedili obravnavani kot stičišči različnih diskurzov, ki sooblikujejo pripovedni diskurz. Ker bo poudarjeno prepletanje diskurzov, bo poudarek na predmetu fokalizacije oziroma na percepciji fokalizatorja (fokalizatorjev).

\subsection{Metodološki pristop}

Pri poskusu detekcije fokalizatorja se bom nekoliko odmaknila od uveljavljenih tipologij pripovedovalca in se osredotočila na kategorizacijo pripovedovalca glede na pripovedne položaje poročanja, razlaganja in presojanja (Zupan Sosič, 2014, 54; Phelan, Martin, 1987, 93-96; Harlamov, 2010, 33-46; Bal, 1997, 36-43), ki so skupni vsem tipom pripovedovalca in ki poudarjajo njegovo pretočnost. Oprla se bom na delitev pripovedovalca na prvoosebnega (Ich-Erzählform) in tretjeosebnega (Er-Erzählform) Monike Fludernik (2006, 42-44), ki temelji predvsem na označevanju prvoosebnega pripovedovalca kot aktivnega ali pasivnega udeleženca v zgodbi (homodiegetični pripovedovalec) in tretjeosebnega pripovedovalca kot instanco, ki je izven zgodbe, o kateri pripoveduje (heterodiegetični pripovedovalec). Na podoben način pripovedne instance definira tudi Mieke Bal, ki trdi, da v pripovednem besedilu najdemo zgolj dva tipa pripovedovalca: tistega, ki sodeluje v zgodbi, in tistega, ki ni del zgodbe (Bal, 1997, 9). Svojo metodološko odločitev utemeljujem z ugotovitvijo zgoraj omenjenih raziskovalk, da je glede na prepletenost pripovednih situacij in pripovednih položajev $\mathrm{v}$ modernih besedilih bolj smiselno raziskovati in poudarjati njihovo sinkretičnost in prepletenost kot vztrajati pri razvoju natančne terminologije. Ta ugotovitev o sinkretičnosti in prepletenosti pripovednih situacij povzroči tudi razmišljanje o kategoriji nezanesljivosti pripovedovalca kot o stalnici, ki je v določeni meri stalno prisotna $\mathrm{v}$ besedilih, ne glede na tip pripovedovalca.

\subsection{0 fokalizaciii v romanih}

Pojem fokalizacija je v naratologijo uvedel Gérard Genette, ki v monografiji Discourse du récit (1972) vzpostavi kritičen odnos do ravni metaliterature oziroma refleksije ter uvede razliko med subjektom govora (pripovedovalec) in subjektom gledanja (fokalizator). Fokalizacijo lahko do določene mere izenačimo s perspektivo. Čeprav sta pojma skoraj sopomenki, je pomen perspektive vendarle nekoliko splošnejši in lahko zajema tako glas kot oči, saj v figurativnem pomenu predstavlja svetovni nazor ali ideologijo (Wales, 1990, 363; Zupan Sosič, 2017, 181) 
pripovedovalca oziroma lika, medtem ko je interes žariščenja ali fokalizacije usmerjen predvsem v instance, objekte prikazanega sveta. Interes fokalizacije je nekoliko bolj epistemološke narave, saj je ne zanima antropomorfna figura fokalizatorja. Povezana je s pripovedovanjem, vendar je njeno bistvo $v$ načinu gledanja in vprašanju, kdo vidi. Genette jo definira kot zapornico med avtorjem in bralcem, ki opozarja na zamolčane, neustrezne ali nezajete dele pripovedi (prim. Genette 1992, 242). Tesno je povezana s terminom perspektiva, ki je v literarni vedi prisoten že od 19. stoletja in označuje »usmerjanje narativne informacije « (Zupan Sosič, 2014, 63), kar sugerira vzpostavljanje analogije s filmom in kotom prikazovanja zgodbe (prim. Zupan Sosič 2014, 62-64; Biti 1997, 101).

Genettova klasifikacija fokalizacije je tridelna; deli se na ničto, notranjo in zunanjo. Ničta je značilna za ekstradiegetičnega vsevednega, tretjeosebnega pripovedovalca, ki ve več kot lik; notranja je omejena na gledišče oziroma žariščenje intradiegetičnega lika (pripovedovalec ve toliko kot lik); zunanja fokalizacija ali t. i. »camera eye« tehnika je omejena na zunanjost lika brez vpogleda v njegova čustva in razmišljanja (Martínez, Scheffel, 2016, 67-71; Zupan Sosič, 2014, 64; Jahn, 1996, 243). Notranja fokalizacija se deli na trdno enožariščno (dosledno uveljavljanje perspektive), sprejemljivo (spreminja se glede na predmet prikazovanja) in večžariščno (dogodek je osvetljen $\mathrm{z}$ različnih gledišč). Lahko rečemo, da Genette določa tip fokalizacije glede na eksplicitnost predstavljenih informacij. Po njegovem ima tisti, ki vidi, vlogo posrednika med avtorjem in bralcem. Tako pri ničti fokalizaciji skoraj ni filtracije informacij, saj ima pripovedovalec neomejen vpogled $\mathrm{v}$ dogajanje in razmišljanja likov, medtem ko je pri zunanji fokalizaciji zaznavna visoka raven filtracije zaradi omejenosti na zunanjo dejavnost lika.

Postgenettovski naratologi Genettu pogosto očitajo, da je pri tej klasifikaciji počel ravno to, čemur se je skušal izogniti: mešanju kriterijev. Bal tako opazi, da se ničta in notranja fokalizacija razlikujeta glede na položaj pripovedovalca (v prvem primeru vidi vse, $v$ drugem vidi toliko kot lik), medtem ko se notranja in zunanja fokalizacija razlikujeta glede na položaj lika, ki v prvem primeru vidi, v drugem pa je viden (prim. Bal, 1997, 101). Njen pomemben prispevek je opozarjanje na pomen obstoja objekta fokalizacije, saj se moramo pri določanju fokalizatorja najprej vprašati, kaj je predmet fokalizacije, kako se ta predmet fokalizira in šele nato, kdo je fokalizator. Posledično uvede dva tipa fokalizacije, pri katerih se osredotoči na položaj fokalizatorja v odnosu do zgodbe: zunanjo, v kateri je združila Genettovo ničto in zunanjo, ter notranjo. Pri zunanji je namreč fokalizator pripovedovalec, ki je ekstradiegetični in je izven zgodbe, pri notranji pa je fokalizator lik znotraj zgodbe in je intradiegetični (prim. Bal, 1997, 146-147). 
Kako manipulativno je lahko dejanje fokalizatorja, Mieke Bal pokaže na primeru objektov fokalizacije, ki jih lahko vidi samo en lik, ni pa nujno, da jih vidijo tudi drugi akterji. To je dejstvo, ki ga bralec rad spregleda. Razmerje med vidnimi in nevidnimi objekti za dva lika ali za lik in pripovedovalca kaže na odnos moči med akterjema ter je lahko signal za detekcijo fokalizatorja in njegovih preferenc. Najočitnejši primer je razlikovanje med izgovorjenimi in neizgovorjenimi besedami. Neizgovorjenih besed enega lika drugi lik ne vidi oziroma ne sliši. Tako naj bi avktorialni pripovedovalec prepoznal vidne in nevidne objekte vseh likov; prvoosebni pripovedovalec pa naj bi imel določene omejitve, saj lahko poleg lastnih vidnih in nevidnih objektov dojema samo še ostale vidne objekte. Primer za razmerje med vidnimi in nevidnimi objekti je prizor iz Eine Zierde für den Verein, ko Frieda med sprehodom v gozdu ugotovi, da se je Gustav ranil in da težko hodi. Gustav Friedi noče priznati svojih bolečin, saj misli, da bo tako izpadel šibek. Njegovih komentarjev ona seveda ne sliši. Heterodiegetični pripovedovalec povezuje dogajanje med likoma in poroča o njem:

»Kaj imaš na stopalu? [...]«

»Nič, « odgovori Gustl zaničljivo in se zareži. »Samo majhen žulj!«

No, zdaj mora še z baterijo posvetiti, da mu bo verjela. Tako daleč ga je Frieda pripeljala s svojim ženskim pretiravanjem (Fleißer, 1987, 92). ${ }^{5}$

Številne primere najdemo tudi v Stud. chem. Helene Willfüer, na primer v prizoru, ko glavna junakinja Helene razmišlja o potovanju v vlaku in izčrpana zaspi. Profesor Ambrosius nato prične razmišljati o njej. Na tem mestu je še dodatno poudarjena razlika med vidnimi in nevidnimi objekti, saj poleg tega, da Ambrosius samo razmišlja o Friedi, ona spi. Pripovedovalec pa v vlogi poročevalca in občasnega razlagalca dopolni zamolčano:

»Zdaj pa morate spati [...],« je rekel odločno. Gospodična Willfüer je tiho zagodrnjala, saj je hotela to doživetje skupne vožnje okusiti do zadnje kapljice in $\mathrm{v}$ popolni budnosti. [...]. Ambrosius [...] je pogledal sključeno dekle in začudeno pomislil: [...] To je vendarle ženska (Baum, 1928, 18).

Monika Fludernik (2006, 43) to zmožnost (samo)refleksije vseh tipov pripovedovalca pojasni $\mathrm{z}$ ugotovitvijo, da je pravzaprav vsak pripovedovalec prvoosebni; tisti, ki govori, je vedno »jaz«, osebe, o katerih govori, so »on«, »ona", »vi«, »ti« itd. ${ }^{6}$

5 Vse navedene odlomke iz romanov sta prevedli Sara Gulam in Marjeta Malus.

6 Tu je treba postaviti pod vprašaj trditev Mieke Bal o zanesljivosti dostopa tretjeosebnega avktorialnega pripovedovalca do nevidnih objektov likov, saj je njegovo dojemanje likov pogosto samo predstavljeno kot celostno. Predstavi jih kot nekaj, kar naj bi razumel, a v resnici lahko ta raven razumevanja precej niha, kar bomo videli v nadaljnji analizi omenjenih besedil. 
Prav razmerje med vidnimi in nevidnimi objekti oziroma odnos pripovedovalca ${ }^{7}$ do posameznih objektov z gledišča poročevalca odpre nekoliko drugačen pogled na kategorijo nezanesljivosti pripovedovalca. Ta je bila pogosto vezana zgolj na prvoosebnega pripovedovalca, ne pa na vsevednega, avktorialnega pripovedovalca, čigar vsevednost se z ozaveščanjem vloge fokalizatorja postavlja pod vprašaj.

\subsubsection{Nezanesliivi pripovedovalec in ironija}

$\mathrm{Na}$ področju naratologije se je $\mathrm{z}$ nezanesljivim pripovedovalcem prvi ukvarjal Wayne C. Booth v Retoriki pripovedne umetnosti (1961) in za nezanesljivo pripoved označil tisto, ki je za bralca neverjetna. Ta neverjetnost na bralca deluje tako, da mnenje pripovedovalca označi za nespametno in njegove sodbe za krivične. Nezanesljivost pripovedovalca je odvisna predvsem od sovpadanja z vrednotami implicitnega avtorja in implicitnega bralca, ki naj bi predstavljale "podobo o normah, prepričanjih, svetovnem nazoru itd., ki jih delo zastopa« (Booth, 2005, 224 v: Harlamov, 2010, 34-35). ${ }^{8}$

Za nezanesljivega najpogosteje označujemo prvoosebnega pripovedovalca, ki je hkrati glavni lik v pripovedi in je preveč moralno izkrivljen, lažniv ali naiven, da bi lahko verodostojno opisal določeno dogajanje. Za bralca naj bi bilo njegovo stališče nedojemljivo, z njegovim značajem pa naj se ne bi mogel poistovetiti (Fludernik, 2006, 179). Monika Fludernik tako kategorijo nezanesljivosti predstavi kot značilnost zgolj prvoosebnega pripovedovalca, ki ni zanesljiv, ker odstopa od družbeno uveljavljenih norm ali jih krši. To so najpogosteje ljudje v norišnicah, nemoralni člani družbe ali naivneži, ki ne vidijo ozadja in ne razumejo časa, v katerem živijo.

Nezanesljivega pripovedovalca nekoliko bolj celostno predstavita Martínez in Scheffel (2016, 100-112), saj kategorije nezanesljivosti ne definirata na podlagi tipa pripovedovalca. Zanju je bistvo nezanesljivosti v tem, da imajo trditve pripovedovalca drugačen in privilegiran status $\mathrm{v}$ odnosu do trditev likov: te naj bi bile $\mathrm{v}$ okviru pripovednega sveta nujno resnične. Trditve likov pa so resnične ravno toliko, kolikor

7 Tu je mišljeno, da je pripovedovalec lahko homodiegetični (je del pripovedi) ali heterodiegetični (ni del pripovedi). Za razčlembo med ekstradiegetičnim in intradiegetičnim pripovedovalcem ter med heterodiegetičnim in homodiegetičnim pripovedovalcem je treba pojasniti Genettovo tipologijo pripovedovalca, ki jo je razložil v delu Figures III (1972). Ekstradiegetični in intradiegetični pripovedovalec sta kategoriji, ki razčlenjata pripovedne ravni. Kot kategoriji sta bolj povezana s fokalizacijo in-vprašanjem, kdo vidi oziroma kje je tisti, ki vidi. Ekstradiegetični pripovedovalec je tako prvi pripovedovalec, pripovedovalec okvirne zgodbe. Heterodiegetični in homodiegetični pripovedovalec sta vezana na kriterij prisotnosti pripovedovalca v zgodbi, ki jo pripoveduje, ter na raven vpletenosti pripovedovalca v zgodbo (prim. Fock, 2014, 98; Martínez, Scheffel, 2016, 85-86).

8 Nekoliko problematična je Boothova opredelitev implicitnega avtorja kot seštevka norm in svetovnega nazora, ki jih delo predstavlja. Implicitni avtor naj bi narekoval naše doživetje dela in insinuiral prisotnost avtorja. Kognitivni naratologi (Nünning, Zerweck) zavračajo ta pristop ter v ospredje postavljajo bralca in njegovo vedenje o resničnem svetu. Harlamov predlaga upoštevanje obeh vidikov, saj sta tako Boothov kot kognitivni pristop preveč pomanjkljiva in nezadostna za celovitejšo opredelitev nezanesljivega pripovedovalca. Več v: Harlamov, 2010, 34-36. 
jih potrdi ali zanika pripovedovalec. Kaj pa se zgodi, ko izstopimo iz pripovednega sveta, ko primerjamo trditve likov in heterodiegetičnega pripovedovalca ter najdemo sledi nezanesljivosti tako na eni kot na drugi strani? Scheffel in Martínez te sledi nezanesljivosti razložita s pojavom ironije v tekstu. Obstajajo torej tudi pripovedi, $\mathrm{v}$ katerih heterodiegetični pripovedovalec vsaj delno izgubi privilegiran položaj, saj se izkaže, da so njegove trditve vsaj delno neresnične, nezanesljive ali neutemeljene. Njegovo nezanesljivost je mogoče najbolje razložiti s pojavom ironije in ironične komunikacije, v kateri je treba razlikovati med implicitnim in eksplicitnim sporočilom. Avtorja poudarjata, da sta lahko tako fiktivni (heterodiegetični) pripovedovalec kot lik ironična in da se posebna kakovost teksta pokaže ravno takrat, ko v njem najdemo dva izvora ironije (to sta lahko literarni lik in pripovedovalec ali dva literarna lika). Ironični so predvsem tisti deli besedila, $\mathrm{v}$ katerih se opisovanje pripovedovalca ne sklada $\mathrm{z}$ obnašanjem ali izjavami likov, ali ko pripovedovalec nasprotuje lastnim izjavam. Tako v Stud. chem. Helene Willfüer pripovedovalec opisuje težke razmere, v katerih delajo znanstveniki. Našteva delovne naloge posameznih znanstvenikov, proti koncu odlomka stopnjuje ironične opazke in komentira, kako asistent v laboratoriju iz čistega zadovoljstva do tretje ure zjutraj sestavlja skelete. Heterodiegetični pripovedovalec se tako hkrati posmehuje lastnemu poročanju in objektu poročanja:

Fizik Biehlmeyer se je zastrupil z živim srebrom. Postal je starec brez zob [...]. Tik pred ciljem bo umrl. In pomočnik za anatomijo Hörselmann se je ponoči iz čistega zadovoljstva predajal znanosti in do treh zjutraj buden sestavljal okostja ... (Baum, 1928, 24).

Za primer iz romana Eine Zierde für den Verein navajam odlomek, v katerem pripovedovalec s stališča poročevalca opiše vzorno nuno, sestro Euphebio, ki se je popolnoma prilagodila strogemu življenju v samostanu. Pripovedovalec s pretirano idealizacijo in naštevanjem njenih vlog ironizira njeno obnašanje, kar zbudi dvom o njeni prisebnosti:

To je bolničarka Ephebia, predana duša, obdana s svetniškim sijem, ki živi v slogu Frančiška Asiškega. Neštetokrat se po prstih in s pladnjem v rokah povzpne čez štiri stopnice $\mathrm{v}$ sobo na vogalu v četrtem nadstropju (Fleißer, 1987, 63).

Lahko rečemo, da pripovedovalec v obeh odlomkih poroča o dogodkih, vendar se ta primarna vloga poročevalca izmenjuje $\mathrm{z}$ vlogo presojevalca. To prepletenost vlog povzročata nezanesljivost pripovedovalca in ironični ton.

Poleg dvoma o kompetentnosti in zanesljivosti nezanesljivega pripovedovalca je v naratoloških raziskavah prisoten dvom o zmožnosti katerega koli tipa pripovedovalca, da celostno in objektivno prikaže zgodbo, o kateri pripoveduje. Vsak, tudi najbolj 
zanesljiv avktorialni pripovedovalec ima namreč tudi določene slepe pege. ${ }^{9}$ Genette pove, da je s pojmom fokalizacija pravzaprav mislil na omejevanje polja vsevednosti in da, ko je definiral ničto fokalizacijo, ni mislil, da je ta vseskozi prisotna v tekstu, da pa je dominantna (2010, 216-218).

\subsubsection{Nezanesljivi pripovedovalec in fokalizacija}

$\mathrm{V}$ tem poglavju se bomo lotili praktične naloge, detekcije fokalizatorja $\mathrm{v}$ povezavi s kategorijo nezanesljivosti pripovedovalca. Po Mairju $(2015,272)$ so signali zanesljivosti oziroma nezanesljivosti v pripovednem tekstu vsebinske, perspektivne (fokalizacija) in jezikovno-formalne narave. Tipični vsebinski signali nezanesljivega pripovedovalca so na primer nasprotja, manjkajoče informacije o dogodkih ali likih, nasprotja med likom in pripovedovalcem ter pogosti paradoksi; tipični perspektivni signali nezanesljivosti so kopičenje izrazito subjektivnih vrednotenj, monologi avtodiegetičnega pripovedovalca (opisi), eksplicitna tematizacija in potrjevanje lastne pripovedovalske zanesljivosti; tipični jezikovno-formalni signali nezanesljivosti so nejasno formulirana stališča, eliptični stavki, empatična uporaba besed in eksplozivni stil pripovedovalca.

Nezanesljivega pripovedovalca lahko s fokalizacijo povežemo predvsem takrat, ko v tekstu ni dominanten zgolj en tip fokalizatorja, temveč si nasprotujeta vsaj dva dominantna fokalizatorja. $\mathrm{V}$ takih primerih prihaja do izražanja dvoma, pojavljajo se ironični komentarji. Genette $(2010,218)$ razloži, da do tovrstnih razlik pride zaradi položaja akterjev v zgodbi, ki delujejo kot zapornica, saj prepustijo samo informacije, ki jih določena situacija dovoljuje. $V$ določenih primerih lik ne more izgovoriti vseh za razumevanje potrebnih informacij in jih zadrži zase (paralipsa). Tako na primer v Eine Zierde für den Verein pripovedovalec po prepiru Gustla in Friede, v katerem ga je prizadela s svojimi naprednimi stališči, Friedo označi za »hudičevo babo« in s to izjavo stopi na Gustlovo stran: "Za to bi ti morala dati pravico že prej', je razločno dejala Luciferjeva hči. 'Takoj bi namreč želela oditi stran od tebe.' « (Fleißer, 1987, 118). $\mathrm{V}$ nasprotnem primeru, če jih izgovori, to dejanje razumemo kot neprimerno, saj je izgovoril več, kot situacija dopušča (paralepsa).

Najpogostejši signali nezanesljivosti v obeh obravnavanih tekstih so nasprotja med liki oziroma med pripovedovalcem in likom. Za primer nasprotja v romanu Eine Zierde für den Verein navajam prizor, v katerem Gustl poskuša Friedo prepričati, naj

9 Menim, da so ravno te slepe pege, ki jih zasledimo v tekstu, signal za nezanesljivost, ki je lahko večja ali manjša, kar je odvisno od tipa pripovedovalca, njegove aktivnosti in udeležbe v zgodbi ter od pripovedne ravni. Znamenja nezanesljivosti se kažejo v obliki dvoma, ironije, naivnih sodb itd. Za obravnavana romana je značilno, da se te slepe pege delijo na dva enakomerna dela (na pripovedovalca in lik v Stud. chem. Helene Willfüer oziroma na pripovedovalca in like v Eine Zierde für den Verein). 
pusti službo trgovske potnice, ker sam ne zmore uspešno voditi trgovine. Želi si, da bi brez plačanega nadomestila prevzela del obveznosti. Smeji se njenim zahtevam, a pravzaprav ne razume njenega sporočila. Misli si, da je Luciferjeva hči, glede na to, kar si upa izgovoriti, ironičen je, a več kot praznih groženj ne izusti. Pri tretjeosebnem pripovedovalcu je opazno žariščenje tako z Gustlove kot Friedine perspektive:

$» \mathrm{~V}$ Ameriki so si moški in ženske v pomoč, « [...]

»Tukaj ni Amerika.«

Tukaj je vendar Frieda, ki je leta in leta opravljala moško delo.

Kako bo to videti, ko se bo Frieda poročila? Adijo svoboda!

»Na to sploh ne smem pomisliti, « pravi Frieda.

Gustl se zareži (Fleißer, 1987, 118).

$\mathrm{V}$ Stud. chem. Helene Willfüer se proti koncu romana, od strani 209 do 227, pripovedovalec distancira od zgodbe mlade znanstvenice Helene, tako da pripovedovanje prepusti zgolj njej. Na dvajsetih straneh se nizajo pisma, ki jih je Helene pošiljala prijatelju Kranichu, vendar njegovih pisem ne vidimo. V pismih ga obvešča o svojem stanju in poteku nosečnosti. Takoj po končanem zadnjem pismu in opisu poziranja Helene slikarju Dartschenku se vključi pripovedovalec in se na bralce obrne z vprašanjem, ali vidimo, kako težko se tej mladi ženski godi in koliko preizkušenj in težkih trenutkov mora prestati, če hoče nadaljevati kariero. Helene je namreč pozirala popolnoma gola, in to ob koncu nosečnosti. Dramatičnost njenega položaja pripovedovalec poudari z nizanjem vprašalnih stavkov ter naštevanjem stvari in sredstev, brez katerih je bila primorana živeti iz dneva $\mathrm{v}$ dan:

Ali vidimo Heleno Willfüer, kako je videti v teh trenutkih? Ali jo lahko vidimo, kot jo vidi slikar Dertschenko [...]? Ali jo vidimo, kako nezmotljivo sledi svoji poti, kako ji uspe brez spanca, hrane in strehe nad glavo iti prek mej človeške zmogljivosti? (Baum, 1928, 227-228).

Več kot očitna je biblična formula, s pomočjo katere pripovedovalec kot poročevalec predstavi življenjsko pot mlade ženske od njenih izredno težkih začetkov, s številnimi skušnjavami (nenačrtovana nosečnost, ponovno pisanje disertacije zaradi bolniške odsotnosti mentorja, smrt otrokovega očeta), do kariere uspešne in mednarodno priznane znanstvenice. Distanca pripovedovalca in njegova številna vprašanja po koncu pisemskega dela romana pokažejo na kritično plat zgodbe. Kritični bralec začne preizpraševati njene postopke ter jo dojemati kot osebo iz mesa in krvi, saj ga pripovedovalec odkrito vabi k razmisleku.

Če povzamemo: na prvi pogled lahko rečemo, da je v tekstih dominantna zunanja fokalizacija, vendar ko se lotimo natančnejše analize, ugotovimo, da je prevladujoča fokalizacija pravzaprav tista med zunanjo in notranjo, ki je 
spremenljiva, saj se njena perspektiva spreminja glede na predmet prikazovanja in je odvisna od hierarhičnega položaja likov, ki ves čas niha. Prav tako odlomki, v katerih pripovedovalec pripovedovanje prepusti liku s ciljem ozaveščanja dualnosti oziroma polarizacije, prisotne v tekstih, omajajo dominantnost zunanje fokalizacije. Ti prehodi med tipi fokalizatorja, ki so neposredno povezani z nezanesljivostjo pripovedovalca, imajo za posledico izražanje dvoma skozi ironijo, ki kaže na zavedanje položaja akterjev zgodbe.

\section{Zaključek}

Pripovedovalec je tisti odločilni element v pripovedi, ki zgodbo filtrira, jo razstavlja in na sebi lasten način ponovno sestavlja. Kot kritični bralci na ta postopek filtracije zgodbe, ki za pripovedovalca ni vedno enostaven, postanemo posebej pozorni $\mathrm{v}$ trenutku, ko v pripovednem besedilu naletimo na kopičenje določenih struktur, na zamolčane ali prehitro končane dele ter na stičišča $\mathrm{v}$ zgodbi, ki zbujajo dvom. V takih trenutkih se pojavlja pragmatično vprašanje, zakaj je tako. Zakaj določene elemente ponavlja ali poudarja, druge pa samo bežno omeni?

$\mathrm{V}$ analizi smo pokazali, kako ironija in nezanesljivost pripovedovalca osvetlita odnos pripovedovalca do zgodbe, ki jo pripoveduje, in odločilno sooblikujeta strukturo pripovedi. Kot smo pokazali, je bistvo nezanesljivosti to, da imajo trditve pripovedovalca drugačen in privilegiran status v odnosu do trditev likov: te naj bi bile v okviru pripovednega sveta nujno resnične. Ugotovili smo, da pripovedovalec pravzaprav preizprašuje dogajanja, ki jih pripoveduje, ne zavzema dokončnih stališč in preprosto izraža dvom. Če so njegovi komentarji ironični, je resnica, ki jo pripoveduje, implicitna, kot je implicitno sporočilo, ki ga mora bralec razbrati iz ironičnega sporočila. Zato lahko sklepamo, da njegovo poročanje deluje kot povezovalni element, ki samo navidezno zapolni zamolčane dele zgodbe.

Naratološko gledano se pozornost pri raziskovanju fokalizacije $\mathrm{v}$ povezavi $\mathrm{z}$ nezanesljivostjo pripovedovalca preusmeri v strukturo pripovednega besedila, saj predmet preučevanja postanejo ravno postopki filtracije zgodbe. Pozornost pritegneta pripovedovalec ter njegov način oziroma modus posredovanja med pripovedjo in zgodbo, ki je v tem primeru ironičen ter temelji na poudarjanju nasprotij, nezmožnosti ustalitve ženskih likov in njihovi raztrganosti med dvema poloma. Ta raztrganost označuje prehodno in negotovo obdobje, $\mathrm{v}$ katerem nova ženska, ki (povedano s feministično-marksističnega vidika) začenja ozaveščati, kako $\mathrm{v}$ procesu opuščanja patriarhalnega načina življenja paradoksalno začne delovati kot moški, kar ji sicer delno omogoči preživetje, v veliki meri pa začne delovati tako, kot si ne želi, in ostane ujeta v družbi, ki jo bo zavračala kot neprilagojenega posameznika. 


\section{Bibliografija}

Bal, M., Narratology. Introduction to the theory of narrative, Toronto 1997.

Baum, V., Mg. chem. Helene Willfüer, Berlin 1928.

Biti, V., Pojmovnik suvremene književne teorije, Zagreb 1997.

Fleißer, M., Eine Zierde für den Verein, Frankfurt na Majni 1987.

Fludernik, M., Einführung in die Erzähltheorie, Darmstadt 2006.

Fock, I., Več kot predgovor, »Urednik« Pepite Jimenez, Vestnik za tuje jezike 6/1, 2014, str. 95-106.

Genette, G., Die Erzählung, München 2010.

Harlamov, A., Nezanesljivi pripovedovalec v sodobnem slovenskem romanu, Jezik in slovstvo 55/1-2, 2010, str. 33-46.

Jahn, M., Windows of focalization, Deconstructing and Reconstructing a Narratological Concept, Style 30/2, 1996, str. 241-267.

Kracauer, S., Die Angestellten. Aus dem neuesten Deutschland, v: Kracauer, S., Schriften 1, Frankfurt Frankfurt na Majni 1971.

Lethen, H., Verhaltenslehren der Kälte, Frankfurt na Majni 1994.

Mair, M., Erzähltextanalyse, Modelle, Kategorien, Parameter, Stuttgart 2015.

Phelan, J., Martin, M. P., The lessons of Weymouth, Homodiegesis, Unrealibility, Ethics and the Reamains of the Day, v: Narratologies, New perspectives on Narrative Analysis (ur. Herman, D.), Columbus 1987, str. 88-109.

Schüller, L., Vom Ernst der Zerstreuung. Schreibende Frauen am Ende der Weimarer Republik, Bielefeld 2005.

Stanzel, F., Theorie des Erzählens, Göttingen 1989.

Wales, K., Dictionary of stylistics, London, New York 1990.

Zupan Sosič, A., Pripovedovalec in fokalizacija, Primerjalna književnost 37/3, 2014, str. $47-72$.

Zupan Sosič, A., Teorija pripovedi, Maribor 2017.

Živkovič, D. (ur.), Rečnik književnih termina, Beograd 1985. 


\section{Sara Gulam}

\section{Nezanesljivi pripovedovalec, fokalizacija in ironija v romanih Stud. chem. Helene Willfüer Vicki Baum in Eine Zierde für den Verein Marieluise Fleißer}

Ključne besede: Vicki Baum, Marieluise Fleißer, Weimarska republika, pripovedovalec, fokalizacija, ironija, nezanesljivi pripovedovalec

$\mathrm{V}$ članku Nezanesljivi pripovedovalec, fokalizacija in ironija v romanih Stud. chem. Helene Willfüer Vicki Baum in Eine Zierde für den Verein Marieluise Fleißer sem raziskovala mehanizme pripovednega besedila, ki fokalizatorju omogočajo, da pride na površje in postane viden. Ukvarjala sem se $\mathrm{z}$ odnosom med pripovedovalcem in fokalizatorjem $\mathrm{v}$ omenjenih delih, ki sta nastali $\mathrm{v}$ času Weimarske republike. Obravnavam ju kot moderni besedili, vkaterih sta pripovedovalec in fokalizator pretočni in sinkretični kategoriji. Po kratki sistematizaciji fokalizacije, ki jo je v naratologijo uvedel Gérard Genette, sem raziskovala povezavo med ironijo in nezanesljivim pripovedovalcem na eni strani ter fokalizatorjem na drugi. $\mathrm{V}$ analizi mi je uspelo dokazati, da lahko nezanesljivega pripovedovalca s fokalizacijo povežemo predvsem takrat, ko v tekstu ni dominanten zgolj en tip fokalizatorja, temveč si nasprotujeta vsaj dva dominantna fokalizatorja. Na konkretnih primerih sem pokazala, kako ironija in pripovedovalčeva nezanesljivost osvetlita odnos pripovedovalca do zgodbe, ki jo pripoveduje, in odločilno sooblikujeta strukturo pripovedi. 
Sara Gulam

\section{Unreliable Narrator, Focalization and Irony in the Novels of Stud.chem. Helene Willfüer by Vicki Baum and Eine Zierde für den Verein by Marieluise Fleißer}

Keywords: Vicki Baum, Marieluise Fleißer, Weimar republic, narrator, focalization, irony, unreliable narrator

In the article Unreliable narrator, focalization an irony in the novels of Stud. chem. Helene Willfüer by Vicki Baum and Eine Zierde für den Verein by Marieluise Fleißer, I have researched the mechanisms of narrative text which enable the focalizer to come to the surface and become visible. I deal with the relationship between narrator and focalizer in the previously mentioned works, which were written in the times of Weimar Republic, and are as such treated as modern texts, in which narrator and focalizer are flowed and syncretic categories. After a short systematization of focalization, which was introduced in narratology by Gérard Genette, I have researched the connection between irony and the unreliable narrator on one hand and the focalizer on the other. In my analysis, I was able to prove that the unreliable narrator can be related with focalization, when there cannot be find a dominant type of focalizer. I have shown actual examples of how the irony and the narrator's unreliability enlighten the narrator's relationship towards the story that he tells, and in a decisive measure codesign the structure of narration. 